\title{
A relational approach to deal with ambiguity in multi-actor governance for sustainability
}

\author{
M. Craps ${ }^{1} \&$ M. F. Brugnach ${ }^{2}$ \\ ${ }^{1}$ Centre for Economics and Corporate Sustainability, \\ KU Leuven, Belgium \\ ${ }^{2}$ Faculty of Engineering Technology, University of Twente, \\ The Netherlands
}

\begin{abstract}
Multi-actor governance is considered necessary when the complexity of an issue transcends the knowledge base, decisional power and resources of a single actor. The challenges related to the massive degradation of the natural environment stimulate the recent interest in this approach. One main goal of the collective decision processes in multi-actor governance is the development of common aims that are aligned to local conditions, and that integrate scientific facts and expert opinions with local knowledge. Deciding collectively, as proposed by multi-actor governance, has profound implications for how ambiguous issues are handled, because different actors hold different frames of what is at stake. In this paper we argue for accepting and dealing adequately with ambiguity, instead of trying to eliminate it, as it is an expression of complexity itself. When we conceive knowledge as resulting from embodied interaction processes in and between communities, then ambiguity is the result of different ways of being in and dealing with the world. Such a relational view directs the attention to boundary crossing practices between different communities that are able to connect and mutually enrich scientific and other ways of knowing. This results in "generative" propositions that open up new interaction possibilities between scientists and other actors to co-create knowledge for sustainability.

Keywords: ambiguity, boundary management, embodied knowledge, framing, governance, local knowledge, multi-actor, relational quality, sustainability.
\end{abstract}




\section{Introduction}

The massive scale at which our planet is devastated by human activities poses a major challenge for the ways decisions are taken regarding our natural resources.

Decision making by governments or market based mechanisms among business companies, are apparently not able to address this challenge adequately. Multiactor governance is proposed as an alternative when complex societal issues are at stake. This means that actors belonging to government, business and civil society jointly steer domains by collaborative interactions (Glasbergen et al. [1] Gray [2] Hovelynck et al. [3]).

However, as each actor has its own frames to conceive reality, decision making situations are confronted with ambiguity. This means that these situations are confused because different actors consider different problems as important, identify different causalities and propose different solutions (Brugnach and Ingram [4], Dewulf et al. [5], Schön and Rein [6]). Strategies to deal with ambiguity often aim at eliminating it by imposing one overarching, superior, integrating or whatever unique frame, to arrive at the best solution (Dewulf et al. [7]). But these strategies are counterproductive for tackling complex sustainability issues as they obfuscate specific interests that are served at the expense of others and exclude valuable types of knowledge to solve issues at a whole systems level (Brugnach and Ingram [4]).

When ambiguity is considered as the result of the cognitive frames of the actors, that deform their view on reality and mislead their opinions, scientific knowledge is often proposed as the objective way out of this tower of Babel. Actors call on scientists to speak in an unequivocal way about reality "as it is" and its general laws "how it must be" (Latour [8]). When we look to collective decision making from an interactional sense making perspective, such a role for science is an illusion, as we will explain later in this paper. This is not a plea to minimize the added value of scientific knowledge in environmental and other complex societal questions. On the contrary, sciences have developed indispensable instruments, concepts and procedures to establish, negotiate about and act upon most of the phenomena that are part of our daily life world. But as different actors with different questions call on different disciplinary specialists this can only add to the ambiguity of the situation. Moreover this expectation in a dominating science is not even desirable, as it closes down possibilities for imagining and creating alternative futures.

In this paper we argue for embracing instead of eliminating ambiguity, because it is an expression of complexity itself. From a sense making perspective, knowledge is considered as the result of an active process of "carving out" data and relations from the continuous and diffuse flow of sensorial impressions (Weick [9]). This knowledge as sense making happens necessarily from a particular perspective, driven by specific interests and in embodied interaction processes in communities (Bourdieu [10], Wenger [11]). Ambiguity in collective decision situations appears then as the result of the confrontation between different ways of being in the world and dealing with the world of different communities. The relational view that we propose in this paper directs the attention to boundary 
crossing joint practices between these communities that are able to connect and mutually enrich their ways of knowing, including between different disciplinary paradigms and other types of knowledge. Looking in this way to collective decision situations opens up new interaction possibilities between scientists and other actors to co-create knowledge that is better able to cope with the challenges of complexity and inclusion.

In what follows we will first clarify the distinction between government and governance and between transactional and co-creative multi-actor governance. We also explain why the latter is considered necessary in to cope with complex ecological challenges. In the next section we will analyze a positivist, a cognitive and a relational sense making approach, relating them to unilateral, transactional and co-creative strategies to conceive and deal with ambiguity. Finally we will indicate some consequences of a relational approach for collective decision making, including scientists.

\section{Complex socio-ecological problems and multi-actor governance}

It may seem unrealistic to argue for multi-actor governance when a violent destruction of the natural resources, a "ravage of the planet", is taking place at an unprecedented scale and pace. The urgency of the environmental crisis seems to call for a hard "authoritarian" approach, which can impose limits, preferably on a global level. However, the recent history of international environmental policy making demonstrates that this is not an option. Binding agreements are rare, were hard to arrive at and have often not the expected impact. Indeed, there are ethical and practical considerations limiting this option. It implies an actor with sufficient power, knowledge and legitimacy to design, impose and follow up effective policy measures on an international scale. Such a unilateral governmental approach may eventually work for "simple" problems, when there is high predictability and a broad consensus about the value of the outcomes of policy measures, but this is not the case for complex environmental issues (Brugnach and Ingram [4], Folke et al. [13], Scharmer and Kaufer [14]).

In the Western world, the steering role of governments has been questioned insistently as inefficient (Hovelynck et al. [3], Huxham [15]). Governments are then presented as a burden and business actors should be allowed to trade as free as possible to maximize economic efficiencies (Scharmer and Kaufer [14] refer to this distinction in terms of historical stages, called "traditional awareness" and "ego-system awareness" respectively). However competition in the market leads to strategies of internalizing benefits and externalizing costs as much as possible, at the detriment of actors that are less able to defend their interests and the system wellbeing as a whole (Scharmer and Kaufer [14]). The confrontation with environmental, social, financial and other system crisis, interconnected between local and global level, has fomented the awareness that relying exclusively on market mechanisms is just as inadequate as governmental regulations to deal with these "wicked" problems (Glasbergen et al. [1], Scharmer and Kaufer [14]). 
As a consequence, policy arenas gradually have been complemented with civil society actors, protesting in the name of the victims of the dominant market economy and reclaiming their rights and benefits through social corrections and environmental measures. This is when multi-actor governance comes into play. Collective decision making becomes, then, necessary including not only governments and business companies, but also civil society actors in varying constellations, through formal and informal interactions, according to the issue at hand. Governance expresses the essence of what governments are supposed to do, that is governing or steering societies. The multi-actor governance concept reflects a search for how actors belonging to different sector should respond jointly to emerging challenges, including environmental issues, to better cope with them (Hovelynck et al. [3], Huxham [15], Janoff and Weisbord [16]). It draws on overlapping and complementary insights from different theories like adaptive governance (Folke et al. [13]), multi-actor collaboration (Gray [17]) and social learning (Wenger [11], Bouwen and Taillieu [18]) amongst others.

Governmental actors are then just stakeholders among many others in policy domains. However policy influencing initiatives are not restricted to governmental actors. A variety of actors may take initiatives to achieve their objectives and develop relationships to influence the outcomes. This multi-actor process shapes societal coordination. The patterns that emerge rest on a multiplicity of actors and the networks that develop in this process are - at least to a large extent - selforganizing (Janoff and Weisbord [16]). Governance is then about managing such multi-actor processes. In the order that emerges through the interacting efforts of all the involved actors, 'managing' necessarily means 'co-managing' (Hovelynck et al. [3]).

However an important distinction has to be made between two modes of interactions between the actors, that we will call here "transactional" and "cocreative" (Scharmer and Kaufer [14] refer to this distinction in terms of "stakeholder awareness" and "eco-system awareness" respectively). Transactional multi-actor governance, which has been by far the most dominant in the past decades, is about defending vested interests. Actors consider themselves as separate from the others and focus on their own specific issues. Interactions are often conflictive. They are resolved by bargaining and transacting, based on the principles of distributive negotiations: give (as little as possible) and take (as much as possible) (Fisher and Ury [19]). Although this mode of multi-actor governance has resulted in important social adjustments - the Western so-called social welfare state can be considered as its main outcome - it has not been able to prevent the socio-economic system stretching the planetary boundaries and excluding a major part of humankind from decent living conditions (Scharmer and Kaufer [14]).

Co-creative multi-actor governance is based on principles that resemble integrative negotiation (Fisher and Ury [19]). This means that the involved actors start thinking and acting by identifying with what they share and have in common. They interrelate in informal social systems, based on mutual, open-ended commitment, rather than in bureaucratic structures, not as representatives of single issue institutions, but as authentic persons, mirroring in their interrelations the complexity of the outside world. 
In the next section we will analyze how approaches to deal with ambiguity are related governance and how they affect the relationship between scientists, governments, business and civil society. To this end, we will first describe briefly how a unilateral controlling government (or a controlling business management or any other unilateral governance mechanism) addresses ambiguity by denying it with a positivist approach. Secondly, we will describe how transactional multiactor governance relies on a cognitive approach to ambiguity. Thirdly, we will analyze more in-depth why co-creative multi-actor governance needs a relational approach to help dealing with the ambiguities that arise from collective decision making.

\section{Governance and ambiguity}

Brugnach et al. [12] propose five action strategies to handle ambiguity in environmental management: rational problem solving, persuasion, negotiation, opposition and dialogical learning. The first two options cope with ambiguity by assuming that there is one single way to frame a problem. They are used in controlling governance systems by the actor (government, management) that has the power to take decisions and implement solutions. Opposition and negotiation strategies correspond to multi-actor systems in which different actors defend their interests by holding different frames of reality. A dialogical learning strategy finally considers different ways of framing reality as opportunities to be explored when complex challenges at the level of a whole system are in play. In what follows we explore more in-depth the relationship between these action strategies and a positivist, cognitive and relational approach of dealing with ambiguity.

\subsection{A positivist approach to ambiguity}

From a positivist point of view on knowledge, science has to offer the objective representation of reality, which is predetermined and predictable. Scientists are considered detached observers of a reality, external to themselves. They dispose of specific instruments that allow them to assess the rules governing reality "as it is". Valid knowledge has to comply with strict rules established by paradigmatic communities of specialist experts and is controlled exclusively by peers.

In such a Cartesian understanding of the world, in which object and subject are separated, there is no space for ambiguity because of the belief in one positivist science, as a superior frame that faithfully mirrors reality as it is. Decision makers can justify their decisions by referring to invariable, general and inescapable scientific laws (e.g. evolutionary laws, market laws, etc.). Alternative interpretations of reality are dismissed as subjective, backward or unenlightened.

However, the ecological thinking of the last decades has brought a change in the way in which ambiguity is considered. It became clear that the goal of reaching one objective understanding of the world was unattainable (Latour [8]), Funtowicz and Ravetz [20]. The simple causality relations of positivist science, applied to concrete, complex situations may at best give fragmented and partial solutions for the problems of the decision maker. Often they are even detrimental from the point 
of view of the actors that feel excluded. So, when different actors start to claim their view on what is at stake and what is of value for them in concrete contexts, this view on science, directing towards unilateral control, turns out to be inadequate (Brugnach and Ingram [4], Brugnach et al. [12], Dewulf et al. [7]).

\subsection{A cognitive approach to ambiguity}

Ambiguity is then accepted as the result of the different perceptions, mental models and world views of different stakeholders that have to be incorporated in decision management (Schön and Rein [6], Dewulf et al. [7]). Frames are considered as static cognitive structures in the individual minds of people, determined by antecedent experiences, positional interests and other fixed characteristics. Scholars have developed overarching or integrating frameworks that distinguish different types of uncertainty and ambiguity from the perspective of the decision maker, based on qualitative and quantitative expert judgments (Van Asselt and Rotmans [22], Walker et al. [23]). In this way different frames can be clearly and systematically identified. They belong to interested stakeholders, influencing their subjective perception of what is at stake, and have to be taken into account to complement the objective view of science on the facts "as they speak for themselves".

In the modern Western world, science claimed its unique position by referring to the distinction between facts, to which it has a kind of direct access, and the values held by ordinary people (Latour [8]). This distinction is related to various other dichotomous epistemological distinctions, like that between objective and subjective knowledge, primary and secondary qualities, explicit and tacit (embodied) knowledge, explanation (external causality) and understanding (from within), and others, in which each time the first of both terms has a superior status over the other This distinction is a deeply rooted heritage of Greek philosophy in our science and society (some claim even that the ecological crisis has to do with the alienation as a consequence of conceiving subjects that are disconnected from the surrounding world.) In this distinction, ambiguity is a question of different value-laden frames which has to be dealt with by politicians, representatives of different actors with specific interests (Latour [8]).

However, as Latour [8] argues, scientists can't rely on facts to justify the special qualities of their knowledge, because they are as attached to the unescapable human and social conditions of our existence as other actors. This lack of special status may sound threatening for scientists, but there are better ways to justify the specific quality of their knowledge, e.g. by describing in a transparent way the systematic way in which information is gathered and analyzed. Once they are liberated from the burden of the facts, scientists can and must engage more freely in dialogues with all other actors, including scientists belonging to other disciplines and paradigms.

According to Latour [8] a state of affairs has to be accepted as "truth" (for the time being) not because it corresponds to an objective world, but because the institutional setting pronouncing it, has followed rules that are agreed upon by those participating in the knowledge seeking endeavor. Procedures have to do with rules and regulations that are legitimized and agreed upon by communities of 
practice. They are reifications of practices that have worked in the past (Wenger [11]). These procedures must also be legitimate for those on which the knowledge application will have an impact. The latter means that we can't impose truth on groups that have not been consulted or that have not consented the procedure. Considering knowledge in this way, procedures fixate, and by doing so put boundaries around phenomena belonging to a world in constant flux. They include certain actors and their interests while excluding others. But because of the open emergent nature of complex realities, the knowledge on which decisions are based, can and should always be contested by those that feel excluded.

\subsection{A relational approach to ambiguity}

Decision making in policy studies has drawn predominantly on a cognitive frames approach (Dewulf et al. [7]). However this type of thinking is often not sufficiently aware of the relational nature of knowledge as sense making (Weick [25]). We construct a meaningful world while relating with others. We can only have access to the world and give meaning to our experiences, mediated by our body functions which are anatomically (Lakoff and Johnson [24]) and culturally (Bourdieu [10]) determined, and in interactions with others, by making use of culturally and socially determined concepts and tools (Latour [8]). As a consequence there is no ultimate unequivocal meaning to which decision making can appeal. In this view the world is accepted as inherently ambiguous.

According to Weick $[9,25]$ science offers in vain general knowledge which can be applied by decision makers to predict and control situations in an accurate way, because generalizability and accuracy are mutually exclusive: generalizations are only possible to the degree that we make abstraction of the complex and changing nature of concrete situations. He proposes plausibility as a more adequate knowledge characteristic to be relevant in real life contexts. Meaningful knowledge can never be "self-referential", it's always "meaning-incontext". Plausible knowledge allows actors to intervene in a meaningful way in contexts that are unique constellations of historical and geographical conditions. Contextualizing of knowledge happens by bringing together different types of knowledge, those considered as scientific as well as other types of knowledge from "lived" experience. Plausibility sets in motion joint actions that are able to generate gradually a more full understanding of reality and contribute to the joint construction of a future, which is acceptable and desirable for all involved actors (Bouwen and Taillieu [18]).

There are as many different ways of knowing about a complex reality as there is an infinite number of possible assemblages and processes, because the "accidental" constellation of participants, and the way they relate with each other, is determinant for the knowledge outcome and what will be done with it (Steyaert and Van Looy [26]). Knowledge is generated in a "topical" trajectory (in space: in a collection of different specific contexts) and a "chronological" process (over time, with changing rhythms). At any moment outcomes of this process can be reified (in documents, reports, tables and figures, tools and instruments), but there is always a need of interaction between actors "here and now" to interpret, adapt and actualize this reified knowledge in concrete circumstances (Wenger [11]). 
Relational practices are as necessary as procedures for joint knowledge creation (Bouwen and Taillieu [18], Steyaert and Van Looy [26]). But whereas procedures delineate and fixate, relations are of paramount importance to include new actors and considerations and by doing so allow innovation, which means co-creation of new possibilities for the issue under consideration. Being included is not the same as having the right to answer the questions that are posed by others, it is being considered in your own terms, your questions being taken seriously. Relations have to do with how we connect not only with each other, but also with ourselves and with the broader system of which we are part and to which we contribute (Scharmer and Kaufer [14]). People don't interact as formal representatives of their organization, but as authentic persons. Reciprocity and sensitivity come to the fore (Bouwen and Taillieu [18]). Relations with these qualities generate communities of practice able to come to real dialogue by connecting disparate elements without dissolving the differences. So-called boundary management is very important in such communities: they must be sufficiently closed to function as a real group, but simultaneously enough open to the outside world, to pick up new ideas and emerging opportunities (Gray [2], Wenger [11]).

In the following table we give an overview of the insights of the preceding section.

Table 1: Different types of governance and ways of dealing with ambiguity in policy making.

\begin{tabular}{|c|c|c|c|}
\hline $\begin{array}{c}\text { Type of } \\
\text { governance }\end{array}$ & $\begin{array}{c}\text { Regulate and } \\
\text { control }\end{array}$ & Transactional & Relational approach \\
\hline Focus & $\begin{array}{c}\text { Product - content }- \\
\text { facts }\end{array}$ & $\begin{array}{c}\text { Procedure - } \\
\text { regulations - laws }\end{array}$ & $\begin{array}{c}\text { Process - relations - } \\
\text { involvement }\end{array}$ \\
\hline Ambiguity & $\begin{array}{c}\text { One dominant } \\
\text { frame: ambiguity } \\
\text { denied }\end{array}$ & $\begin{array}{c}\text { Different competing } \\
\text { cognitive frames: } \\
\text { ambiguity recognized } \\
\text { and to be resolved }\end{array}$ & $\begin{array}{c}\text { Interactional framing in } \\
\text { and between } \\
\text { communities: } \\
\text { ambiguity accepted and } \\
\text { to be dealt with }\end{array}$ \\
\hline $\begin{array}{c}\text { Science and } \\
\text { sustainability }\end{array}$ & $\begin{array}{c}\text { Indicating or } \\
\text { calculating one best } \\
\text { solution }\end{array}$ & $\begin{array}{c}\text { Expert panels and } \\
\text { lobbying }\end{array}$ & $\begin{array}{c}\text { Inter- and } \\
\text { transdisciplinary } \\
\text { dialogue }\end{array}$ \\
\hline $\begin{array}{c}\text { Relationship } \\
\text { science - } \\
\text { governments }- \\
\text { business - civil } \\
\text { society }\end{array}$ & Passive & $\begin{array}{c}\text { Conflict and } \\
\text { bargaining }\end{array}$ & $\begin{array}{c}\text { Innovation and change } \\
\text { boundary crossing } \\
\text { relational practices }\end{array}$ \\
\hline
\end{tabular}

\section{Concluding: from avoiding to embracing ambiguity and co-creating knowledge for sustainability}

Decision making as a relational process in which communities define together a domain and develop together solutions, tailored to their jointly designed objectives, sounds attractive, but may be as naïve and detrimental as believing that 
a strong government or companies operating in open markets can solve on their own problems of sustainability. Co-creative strategies imply the assumption of equal access and opportunity to be taken into account. "Changes in knowledge production processes are futile if they are not accompanied by a process of empowerment that guarantees those that need to be included, are granted the rights and possibilities to fully participate" (Brugnach et al. [21]). Transactional multiactor governance is about policy measures guaranteeing structural empowerment, and complements co-creative governance.

Co-creative governance is thus not about withdrawing governments, on the contrary. Economic policy instruments e.g. ("sticks and carrots") can create a socio-economic context favorable for companies and other actors to integrate environmental and social concerns in their own strategies. But these instruments and regulations have to be developed in close collaboration with all relevant societal actors. This implies new roles and functions for governmental actors, e.g. as conveners, brokers or supporters of initiatives taken by other actors. As to companies, they reunite the resources and competencies to develop the world, be it in a devastating or sustainable way. Sustainable business practices that contribute to sustainability from a complex (global and local) systems perspective, are not conceivable for companies in isolation, obsessed by their particular interests. Such practices have to be developed in close collaboration with all stakeholders, including other companies, governments at different levels, and different types of social organizations. All these collaborative initiatives will lead to a blurring of boundaries between sectors and actors, e.g. between the so-called real and social economy.

The ambiguity in and between these blurred societal domains asks for relational practices that are able to link communities in continuously changing constellations (Steyaert and Van Looy [26]). Social scientists have developed so-called "Large Group Intervention methods", based on systems theory, to work constructively with differences at a whole systems level (like Search Conference, World Café, Open Space, Appreciative Inquiry and others, see e.g. Janoff and Weisbord [16]). So called "boundary activities", like prototyping together and outdoor activities, and "boundary objects", like art works, may invite participants to abandon encapsulated knowledge frames and vested interests to explore the boundaries and deal constructively with the ambiguity in those situations. Methodologies can be helpful but they can't be applied mechanistically. It's a question of creatively designing pathways so that diverse groups can arrive deeper in contact with what really matters to themselves, to the others and to the outside world expecting their contribution (Scharmer and Kaufer [14]). Or as McNamee puts it: "There is no method, just watch the relationship" [27].

As to scientists, they should take fully part in these joint knowledge creation processes - hence the importance of action research - in open dialogue with all other interested actors. They must be transparent about the underlying assumptions and implicit values that are inseparable from any knowledge. Their knowledge is valid to the degree it can pass not only peer review but also the review of all involved and well informed actors. That is the idea of "consensual validation": validated by an informed consensus of all actors. This type of validation will also 
generate the energy and political will of the involved actors to engage in the activities that result from it, that is "actionable knowledge" (Bouwen and Taillieu [18]).

We are well aware of the paradoxical endeavor of writing a conceptual paper on relational co-creation to deal with ambiguity. Indeed, an academic paper constitutes an inner contradiction with the principles of relational organizing when making abstraction of concrete persons and situations. Papers like this one become only meaningful when they are interpreted by scientists and lay persons with different backgrounds and they become actionable when they function as "boundary objects" inviting to experiment with relational practices. Notwithstanding limitations and obstacles in the academic and outside world, that favor disciplinary specialization over inter- and transdisciplinary efforts, such a dialogical way of doing sciences is necessary for a sustainable world to be cocreated.

\section{References}

[1] Glasbergen, F. Biermann, A. Mol, \& Elgar, E. (eds.), Partnerships, governance and sustainable development. Reflections on Theory and Practice. Northampton, 2007.

[2] Gray, B. The process of partnership construction : anticipating obstacles and enhancing the likelihood of successful partnerships for sustainable development. In: P. Glasbergen, F. Biermann, A. Mol, \& E. Elgar (Eds.), Partnerships, governance and sustainable development. Reflections on Theory and Practice. pp. 29-48. Northampton, 2007.

[3] Hovelynck, J., Dewulf, A., \& Sips, K., Perspective study: Governance for Cradle to Cradle. OVAM: Mechelen, INTERREG IVC C2CN report, pp. 157, 2010.

[4] Brugnach, M., \& Ingram, H., Ambiguity: the challenge of knowing and deciding together. Environmental Science \& Policy, 15(1), pp. 60-71, 2012.

[5] Dewulf, A., Craps, M., Bouwen, R., Taillieu, T., \& Pahl-Wostl, C., Integrated management of natural resources: dealing with ambiguous issues, multiple actors and diverging frames. Water Science and Technology, 52(6), pp. 115-24, 2005.

[6] Schön, D. \& Rein, M., Frame reflection. Towards the resolution of intractable policy controversies. Basic Books: New York, 1994.

[7] Dewulf, A., Gray, B., Putnam, L., Lewicki, R., Aarts, N., Bouwen, R., \& van Woerkum, C. Disentangling approaches to framing in conflict and negotiation research: A meta-paradigmatic perspective. Human Relations, 62(2), pp. 155-193, 2009.

[8] Latour, B., Politics of nature. How to bring the sciences into democracy. Harvard University Press: Cambridge - London, 2004.

[9] Weick, K.E., Sensemaking in organizations. Thousand Oaks: Sage Publications, 1995.

[10] Bourdieu, P., Le sens pratique, Editions Minuit: Paris, 1980. 
[11] Wenger, E., Communities of Practice and Social Learning Systems. Organization, 7(2), pp. 225-246, 2000.

[12] Brugnach, M., Dewulf, A., Henriksen, H. J., \& van der Keur, P., More is not always better: coping with ambiguity in natural resources management. Journal of environmental management, 92(1), pp. 78-84, 2011.

[13] Folke, C., Hahn, T., Olsson, P., \& Norberg, J., Adaptive Governance of Social-Ecological Systems. Annual Review of Environment and Resources, 30(1), pp. 441-473, 2005.

[14] Scharmer, O., \& Kaufer, K., Leading from the emerging future. From Egosystem to Eco-system economies. (pp. \&-287). Berrett-Koehler Publishers: San Francisco, 2013.

[15] Huxham, C., The Challenge of Collaborative Governance. Public Management, 2(3), pp. 337-357, 2000.

[16] Janoff, S. \& M. Weisbord, Facilitating the whole system in the room. A theory, philosophy and practice for managing conflicting agendas, diverse needs and polarized views. Online. www.futuresearch.net

[17] Gray, B., Collaborating. Finding common ground for multiparty problems. Jossey Bass, 1989.

[18] Bouwen, R., \& Taillieu, T., Multi-party Collaboration as Social Learning for Interdependence: Developing Relational Knowing for Sustainable Natural Resource Management. Journal of Community \& Applied Social Psychology, 14(1), pp. 137-153, 2004.

[19] Fisher, R. \& Ury, W., Getting to yes. Negotiating agreement without giving in. Penguin Books: London, 1981.

[20] Funtowicz, S.O. \& Ravetz, J.R., Uncertainty and quality in science for policy. Kluwer Academic Publisher: Dordrecht, 1990.

[21] Brugnach, M., Craps, M., \& Dewulf, A., Including indigenous peoples in climate change mitigation: addressing issues of scale, knowledge and power. Climatic Change, 2014.

[22] Van Asselt, M. \& Rotmans, J., Uncertainty in perspective. Global Environmental Change, 6, pp. 121-157, 1996.

[23] Walker, W.E., P. Harremoës, P., Rotmans, J., van der Sluijs, J.P., van Asselt, M.B.A., Janssen, P. \& Krayer von Krauss, J.P., Defining Uncertainty: A Conceptual Basis for Uncertainty Management in ModelBased Decision Support. Integrated Assessment, Vol. 4, Iss. 1, 2003.

[24] Lakoff, G., \& Johnson, M., Philosophy in the flesh. Basic Books: New York, 1999.

[25] Weick, K. E. Managing the Unexpected: Complexity as distributed sensemaking. In R. R. McDaniel \& D. J. Driebe eds., Uncertainty and surprise in complex systems, Springer-Verlag: Berlin and Heidelberg, pp. 51-65, 2005.

[26] Steyaert, C. \& Van Looy, B. (eds.), Relational practices, participative organizing. Emerald Group Publishing: Bingley, 2010.

[27] McNamee, S., Taos Institute, Online. www.taosinstitute.net 